\title{
A simple spectrophotometric method for determination of thiamine (vitamin B1) in pharmaceuticals
}

\author{
Khairia Mohammed Al-Ahmary \\ Chemistry Department, Sciences Faculty for Girls, King Abdulaziz University, Jeddah, Kingdom of Saudi Arabia
}

*Corresponding author at: Chemistry Department, Sciences Faculty for Girls, King Abdulaziz University, Jeddah, Kingdom of Saudi Arabia. Tel.: +966.053.4441212. Fax: +966.012.6243883. E-mail address: khairia.alahmary@yahoo.com (K.M. Al-Ahmary)

\section{ARTICLE INFORMATION}

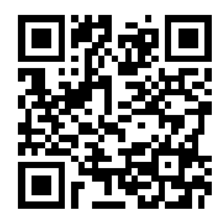

DOI: $10.5155 /$ eurjchem.5.1.81-84.881

Received: 17 July 2013

Received in revised form: 15 August 2013

Accepted: 18 August 2013

Online: 31 March 2014

\section{KEYWORDS}

\section{Thiamine}

Oxidation

Precipitation

Determination

Barium sulphate

Spectrophotometric

\section{Introduction}

Thiamine (Figure 1), known as vitamin B1 (a water soluble vitamin) is a natural nutrient present in many foods and is also added as an essential nutrient in food products. It has been used for the prevention and treatment of beriberi, neuralgia, etc. It is also added to medical doses or vitamin B1 enriched food or drinks. It is necessary for carbohydrate metabolism and for the maintenance of neutral activity [1].<smiles>Cc1ncc(C[n+]2csc(CCO)c2C)c(N)n1</smiles>

Figure 1. Chemical structure of thiamine hydrochloride.

The chemical method most widely used for determination of thiamine, involves the reaction between vitamin B1 and potassium hexacyanoferrate(III) in alkaline solution, followed by extraction of the thiochrome (TC) formed in aqueous phase into an organic phase, which is then measured florimetrically [2]. This procedure is the official U.S.P. method and has been automated by flow injection (FI) with fluorimetric and chemiluminescence detection [3,4]. Other FI methods accomplish the oxidation of thiamine to fluorescent TC using $\mathrm{Hg}$ (II) [5], $\mathrm{Cu}(\mathrm{II})$ [6], strong anionic resins loaded with hexacyanoferrate(II) [7] and electrochemical oxidation [8]. The on-line UV irradiation of thiamine with photometric [9] and fluorimetric detection [10] and the derivatization reaction of the primary amine group with $o$-phthalaldethude in presence of 2-meracapto ethanol using fluorimetric detection [11] have also been proposed.

Thiamine hydrochloride was determined by using the chromatographic method depends on HPLC [12]. Thiamine has been determined gravimetrically by precipitation with silictungestic acid as recommended by British Pharmacopeia [13]. The precipitate as insoluble in water and its molecular formula was described as $\left[\mathrm{C}_{12} \mathrm{H}_{17} \mathrm{~N}_{4} \mathrm{OS}\right]_{2}\left[\mathrm{Si}\left(\mathrm{W}_{3} \mathrm{O}_{10}\right)\right]_{4}$. However, this gravimetric procedure is tedious, once it involves several time consuming steps such as digestion, filtration, heating to dryness and weighting. Also thiamine determined based on the precipitation reaction of thiamine with silicotungstic acid in acidic medium to form a thiamine silicotungstate suspension that is measured at $420 \mathrm{~nm}$ [14]. Thiamine was determined by a spectrofluorimetric method based on the catalytic activity of horseradish peroxidase in the presence of hydrogen peroxide [15].

Two simple and sensitive spectrofluorimetric methods were developed for determination of thiamine by oxidized to thiochrome by iodine in an alkaline medium [16] or oxidized 
with potassium iodate $(\mathrm{V})$ to the colourless product and a stoichiometric amount of iodide ions was formed. The latter reacted with the excess of iodate(V) ions in acidic medium, to form free iodine which oxidized leucocrystal violet to the crystal violet dye [17].

This work describes a simple, rapid and sensitive spectrophotometric method for the determination of thiamine in pharmaceutical preparations. The proposed method is based on the precipitation of sulphur as barium sulphate in acidic medium and measured spectrophotometry at $420 \mathrm{~nm}$.

\section{Experimental}

\subsection{Apparatus}

A double beam Shimadzu (Kyote, Japan) UV-Vis Spectrophotometer, model UV-1650 PC equipped with $1 \mathrm{~cm}$ quartz cells. The bundled software was UV PC personal spectroscopy software version 2.1 (Shimadzu). The spectral bandwidth was $2 \mathrm{~nm}$ and the wavelength scanning speed was $2800 \mathrm{~nm} / \mathrm{min}$. PLS and PCR analyses were carried out by using PLS toolbox software version 2.1-PC for use with MATLABS.

\subsection{Materials}

All chemicals used were of analytical reagent grade. Deionized water was used throughout. Thiamine was supplied by (Sigma-Aldrich), Benerva tablets $50 \mathrm{mg}$ from UK, Doxal tablets $100 \mathrm{mg}$ from USA and Citineurin $5000(100 \mathrm{mg}$ of thiamine) from Merck.

\subsection{Preparation of solutions}

\subsubsection{Stock standard solution of thiamine. $\mathrm{HCl} 100 \mu \mathrm{g} / \mathrm{mL}$}

Accurately weigh $50.0 \mathrm{mg}$ of USP Thiamine. $\mathrm{HCl}$ reference standard solution previously dried by storing over $\mathrm{P}_{2} \mathrm{O}_{5}$ in desiccator. Since reference standard is hygroscopic, take precautions to avoid moisture absorption during weighing. Transfer $50.0 \mathrm{mg}$ of stock standard solution to $500 \mathrm{~mL}$ volumetric flask. Dissolve in acidified $20 \%$ alcohol, and dilute to $500 \mathrm{~mL}$ with additional acidified alcohol. Store in red or amber glass-stoppered bottle in refrigerator. Solution is stable for several months.

\subsubsection{Working standard solutions}

Working standard solutions containing $1-50 \mu \mathrm{g} / \mathrm{mL}$ were prepared by suitable dilution of the stock solution with distilled water.

\subsubsection{Regent solutions}

Standard stock solution of $3 \mathrm{M}$ of $\mathrm{NaOH}, 5 \%$ of $\mathrm{BaCl}_{2}$ in $4 \mathrm{M}$ $\mathrm{HClO}_{4}$ were prepared in one liter by dissolving the suitable weight in deionized water and diluting with water in a calibrated flask to the mark. $\mathrm{H}_{2} \mathrm{O}_{2}$ was prepared freshly for each experiment.

\subsection{Preparation of samples}

Ten tablets were powdered and an amount equivalent to 20 $\mathrm{mg}$ of the thiamine was weighed accurately and dissolved in $100 \mathrm{ml}$ of water using calibrated flask. The solution was filtered through a Whatman no. 1 filter paper and the filtrate and two washings, each of $20 \mathrm{~mL}$, were collected in a $1000 \mathrm{~mL}$ calibrated flask and diluted to volume with deionized water.

\subsection{Procedure}

To thiamine solution (equivalent to $1-50 \mu \mathrm{g} / \mathrm{mL}$ ), five $\mathrm{mL}$ of sodium hydroxide solution and five $\mathrm{mL}$ of hydrogen peroxide were added to oxidized the thiamine and produced sulphate. Then the solution was heated in a water bath at $75^{\circ} \mathrm{C}, 4 \mathrm{~mL}$ of $5 \% \mathrm{BaCl}_{2}$ in $4 \mathrm{M} \mathrm{HClO}_{4}$ was added to precipitate sulphur as $\mathrm{BaSO}_{4}$. Then $4 \mathrm{~mL}$ of glycerol:ethanol (2:1) solution was added (to keep the solid particles suspended in the solution). The mixture was diluted to $25 \mathrm{~mL}$ with deionized water, shaken and cooled. The absorbance and transmittance were measured at $420 \mathrm{~nm}$ against blank. The effect of heating time, concentration of $\mathrm{NaOH}, \mathrm{H}_{2} \mathrm{O}_{2}$ and thiamine were studied. The best conditions were chosen for analysis.

\section{Results and discussion}

Factors affecting the absorbance and percent transmittance

\subsection{Effect of heating time}

The effect of heating time (5-60 min) on absorbance (Abs.) and percent transmittance (\%T.) is shown in Figure 2. As can be seen, the absorbance and percent transmittance remained constant after heating in water bath for $30 \mathrm{~min}$.

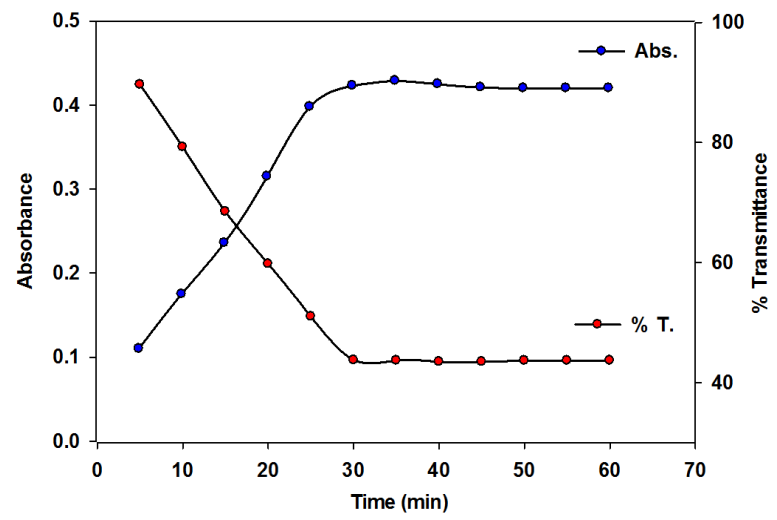

Figure 2. Effect of heating time on absorbance and percent transmittance of $16 \mu \mathrm{g} / \mathrm{mL}$ of thiamine using $1.5 \mathrm{M} \mathrm{NaOH}, 10 \% v: v \mathrm{H}_{2} \mathrm{O}_{2}$.

\subsection{Effect of heating temperature}

The effect of heating temperature $\left(50-110{ }^{\circ} \mathrm{C}\right)$ on absorbance and percent transmittance is shown in Figure 3. As can be seen, the absorbance and percent transmittance remained constant after heating in water bath for $30 \mathrm{~min}$ at $100{ }^{\circ} \mathrm{C}$.

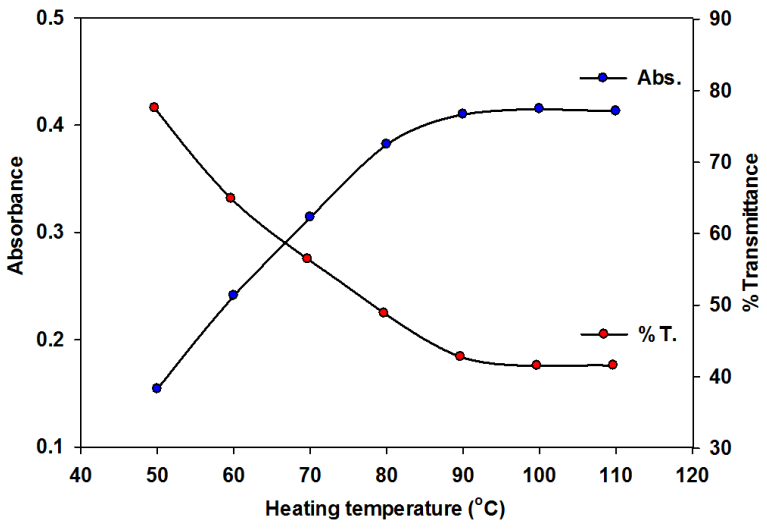

Figure 3. Effect of heating temperature on absorbance and percent transmittance of $16 \mu \mathrm{g} / \mathrm{mL}$ of thiamine using $1.5 \mathrm{M} \mathrm{NaOH}, 10 \% v: v \mathrm{H}_{2} \mathrm{O}_{2}$. 


\subsection{Effect of microwave}

The effect of microwave on time of reaction was studied and the results showed that from 1.5-2.0 min. At 100 Watt gave the maximum of absorbance and minimum of percent transmittance and remained constant. So instead of heating the mixture of thiamin with sodium hydroxide and hydrogen peroxide for $30 \mathrm{~min}$ at $100{ }^{\circ} \mathrm{C}$, the mixture was put in microwave for two min. at 100 Watt.

\subsection{Effect of $\mathrm{NaOH}$ concentration}

The effect of $\mathrm{NaOH}$ concentration $(0.5,1.0,1.5,2.0,2.5$ and $3.0 \mathrm{M}$ ) on the absorbance and transmittance is shown in Figure 4. It can be seen that the absorbance reached a maximum and remained constant and the transmittance reached a minimum and remained constant when the concentration of sodium hydroxide solution is between 1.5-3.0 M. Below this range the absorbance decreased. $1.5 \mathrm{M} \mathrm{NaOH}$ solution was chosen in the analysis.

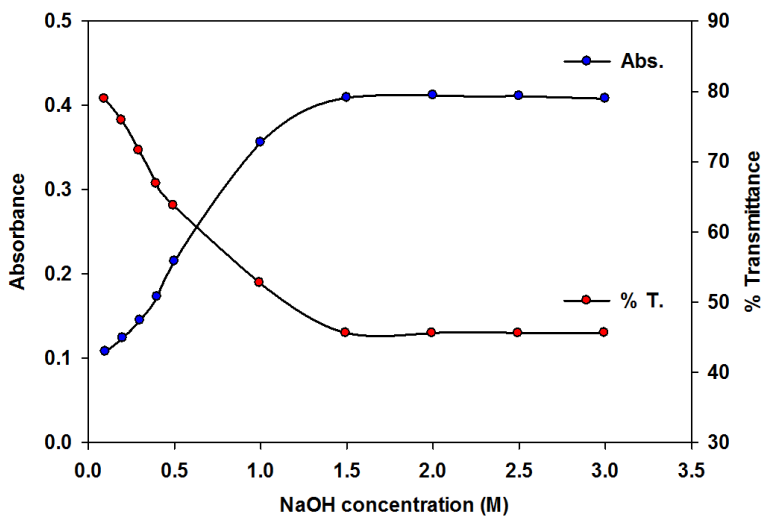

Figure 4. Effect of sodium hydroxide concentration on absorbance and percent transmittance of $16 \mu \mathrm{g} / \mathrm{mL}$ of thiamine using $10 \% v: v \mathrm{H}_{2} \mathrm{O}_{2}$ and microwave for two min. at $100 \mathrm{~W}$.

\subsection{Effect of $\mathrm{H}_{2} \mathrm{O}_{2}$ concentration}

The effect of hydrogen peroxide concentration $(3,6,9,12$ and $15 \% v: v)$ on the absorbance and transmittance has been studied and the results are shown in Figure 5. The figure indicates that the maximum and constant of absorbance and the minimum and constant of transmittance occur when the concentration of hydrogen peroxide between 9-15\% v:v. Therefore $10 \% v: v$ of hydrogen peroxide was selected in the analysis.

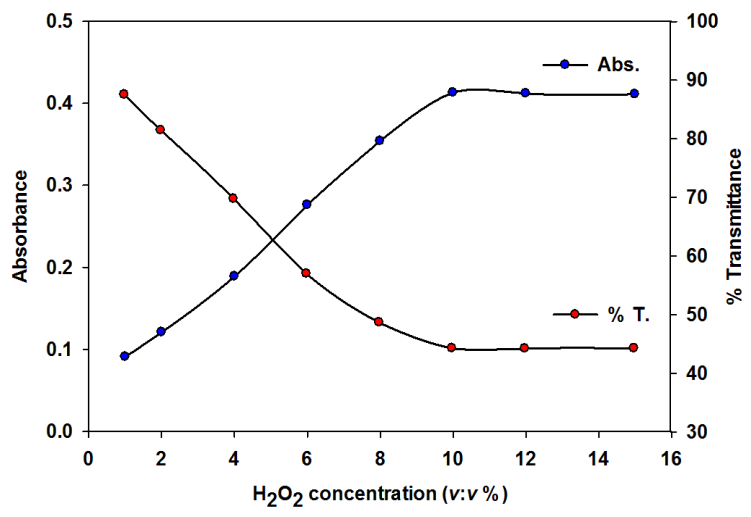

Figure 5. Effect of hydrogen peroxide concentration on absorbance and percent transmittance of $16 \mu \mathrm{g} / \mathrm{mL}$ of thiamine using $1.5 \mathrm{M} \mathrm{NaOH}$ and microwave for $2 \mathrm{~min}$ at $100 \mathrm{~W}$.

\subsection{Effect of thiamine concentration}

The effect of thiamine concentration on the absorbance and transmittance has been studied and the results are shown in Figure 6 . The figure indicates that the increased absorbance and decreased transmittance are linear with thiamine concentration in the range from 2 to $32 \mu \mathrm{g} / \mathrm{mL}$.

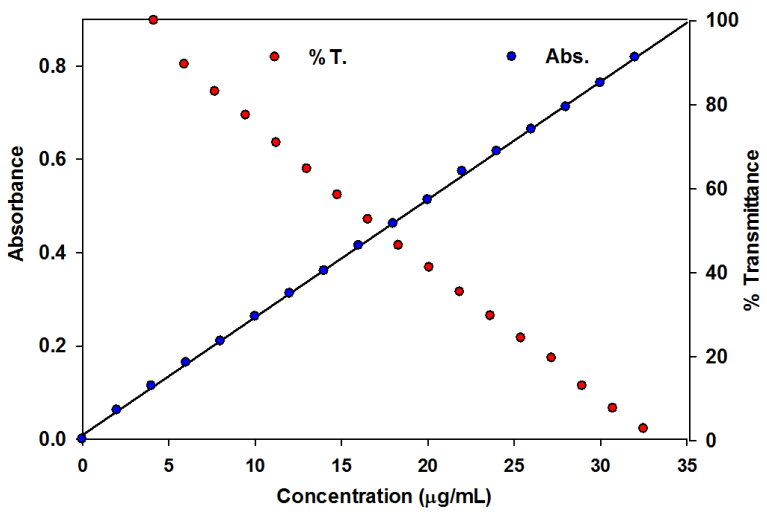

Figure 6. Effect of concentration of thiamine on absorbance and percent transmittance using $1.5 \mathrm{M} \mathrm{NaOH}, 10 \% v: v \mathrm{H}_{2} \mathrm{O}_{2}$ and microwave for $2 \mathrm{~min}$ at $100 \mathrm{~W}$.

\subsection{Calibration curve and sensitivity}

Standard calibration curves for thiamine were determined under the optimized conditions (i.e., heating time, temperature, concentration of $\mathrm{NaOH}$ and $\mathrm{H}_{2} \mathrm{O}_{2}$ ). The molar absorptivities, Sandell sensitivities, regression equations and correlation coefficients were calculated.

The least square method was used to derive the regression equations for the suggested procedures, and the values of the correlation coefficient ranged from 0.9991 to 0.9999 . To validate the analytical procedures, both the detection limit (DOL) and the quantification limit (QOL) were determined [18]. The parameters of the proposed methods are summarized in Table 1.

\subsection{Reproducibility}

To determine the reproducibility of the methods, five different weights of the thiamine were analyzed. The relative standard deviations (R.S.D. \%) were 0.19-0.93\%, suggesting that the proposed methods were reproducible (Table 2). This precision level is appropriate for the simple, fast and sensitivity analysis of thiamine.

\subsection{Selectivity}

The recovery of thiamine was evaluated to determine the selectivity of the described methods. The recovery values ranged from $99.98 \pm 0.17 \%$ to $100.11 \pm 0.07 \%$ (Table 2), indicating the accuracy of the described method. Also the high percentage recovery data show that all of the proposed methods are free from interference

Comparing to the methods for determination of thiamine, the proposed method was more simple, sensitive and accuracy than the others. For example Khan [15] found the linear range from $0.026-16.830 \mu \mathrm{g} / \mathrm{mL}, r=0.9964, \mathrm{RSD}=1.75 \%$, LOD $=$ $0.015 \mu \mathrm{g} / \mathrm{mL}$, Mohamed [16] found that linear range from 10$500 \mathrm{ng} / \mathrm{mL}, r=0.9991, \mathrm{RSD}=0.46-1.02 \%$, Recovery $=97.6 \%$ and Szpikowska-Sroka [17] found the linear range from 0.4-2.4 $\mu \mathrm{g} / \mathrm{mL}, r=0.9998$ and $\mathrm{LOD}=0.19$ and $0.26 \mu \mathrm{g} / \mathrm{mL}$. 
Table 1. Analytical parameters for determination of thiamine.

\begin{tabular}{ll}
\hline Parameters & \\
\hline Beer's law limits $(\mu \mathrm{g} / \mathrm{mL})$ & $2-32$ \\
Limits of detection $(\mu \mathrm{g} / \mathrm{mL})$ & 0.41 \\
Limits of quantification $(\mu \mathrm{g} / \mathrm{mL})$ & 6726.27 \\
Molar absorptivity $(\mathrm{L} / \mathrm{mol} . \mathrm{cm})$ & 0.04 \\
Sandal's sensitivity & $y=2.52 \times 10^{-2} \cdot x+9.20 \times 10^{-3}$ \\
Regression equation * & $9.20 \times 10^{-3}$ \\
Intercept a & $2.52 \times 10^{-2}$ \\
Slope b & $1.90 \times 10^{-3}$ \\
Confidence interval of Intercept $\alpha$ & $1.00 \times 10^{-4}$ \\
Confidence interval of Slope $\beta$ & 0.9998 \\
Correlation coefficient $\left(r^{2}\right)$ &
\end{tabular}

Correlation coefficient $\left(r^{2}\right)$

${ }^{*} \mathrm{y}=\mathrm{a}+\mathrm{bx} ; \mathrm{y}$ : the transmittance of concentration, $\mathrm{x}$ : the concentration in $\mu \mathrm{g} / \mathrm{mL}$.

Table 2. Evaluation of precision of the proposed method on thiamine hydrochloride pure and pharmaceutical formulations *

\begin{tabular}{|c|c|c|c|c|c|c|c|c|}
\hline \multirow[t]{2}{*}{ Sample } & \multicolumn{2}{|c|}{ Thiamine $(\mu \mathrm{g} / \mathrm{mL})$} & \multirow[t]{2}{*}{ Average recovery (\%) } & \multirow{2}{*}{$\begin{array}{l}\text { SD } \\
n=5\end{array}$} & \multirow{2}{*}{$\begin{array}{l}\text { SDE } \\
\mathrm{n}=5\end{array}$} & \multirow{2}{*}{$\begin{array}{l}\text { RSD \% } \\
\mathrm{n}=5\end{array}$} & \multirow{2}{*}{$\begin{array}{l}\text { RSE \% } \\
n=5\end{array}$} & \multirow[t]{2}{*}{ 95\% Conf. } \\
\hline & Taken & Found & & & & & & \\
\hline \multirow{5}{*}{ Thiamine. $\mathrm{HCl}$} & 10 & 10.11 & 100.11 & 0.07 & 0.03 & 0.32 & 0.04 & 0.09 \\
\hline & 15 & 15.01 & 100.04 & 0.05 & 0.02 & 0.19 & 0.02 & 0.07 \\
\hline & 20 & 20.02 & 100.05 & 0.08 & 0.04 & 0.37 & 0.04 & 0.10 \\
\hline & 25 & 24.93 & 99.99 & 0.22 & 0.10 & 0.93 & 0.09 & 0.27 \\
\hline & 30 & 29.99 & 99.98 & 0.17 & 0.07 & 0.74 & 0.08 & 0.21 \\
\hline \multirow[t]{5}{*}{ Benerva } & 10 & 10.01 & 100.12 & 0.13 & 0.06 & 1.28 & 0.06 & 0.16 \\
\hline & 15 & 14.99 & 99.95 & 0.18 & 0.08 & 1.22 & 0.09 & 0.23 \\
\hline & 20 & 19.98 & 99.89 & 0.13 & 0.06 & 0.67 & 0.07 & 0.17 \\
\hline & 25 & 24.99 & 99.96 & 0.22 & 0.10 & 0.87 & 0.11 & 0.27 \\
\hline & 30 & 29.96 & 99.87 & 0.19 & 0.09 & 0.64 & 0.10 & 0.24 \\
\hline \multirow[t]{5}{*}{ Doxal } & 10 & 10.04 & 100.44 & 0.10 & 0.05 & 1.03 & 0.05 & 0.13 \\
\hline & 15 & 15.01 & 100.09 & 0.19 & 0.09 & 1.30 & 0.10 & 0.24 \\
\hline & 20 & 19.98 & 99.92 & 0.16 & 0.07 & 0.79 & 0.08 & 0.20 \\
\hline & 25 & 24.98 & 99.91 & 0.14 & 0.06 & 0.55 & 0.07 & 0.17 \\
\hline & 30 & 30.06 & 100.19 & 0.13 & 0.06 & 0.45 & 0.07 & 0.17 \\
\hline \multirow[t]{5}{*}{$\overline{\text { Citineurin } 5000}$} & 10 & 10.22 & 102.18 & 0.44 & 0.20 & 4.35 & 0.22 & 0.92 \\
\hline & 15 & 14.99 & 99.92 & 0.18 & 0.08 & 1.17 & 0.09 & 0.22 \\
\hline & 20 & 19.99 & 99.96 & 0.19 & 0.08 & 0.93 & 0.09 & 0.23 \\
\hline & 25 & 25.01 & 100.03 & 0.11 & 0.05 & 0.42 & 0.05 & 0.13 \\
\hline & 30 & 30.01 & 100.04 & 0.13 & 0.06 & 0.42 & 0.06 & 0.16 \\
\hline
\end{tabular}

* SD: Standard deviation, n: Number of samples, SDE: Standard deviation error, RSD \%: Relative standard deviation, RSE \%: Relative standard error, 95\% Conf.: Confidence interval.

\subsection{Applications}

The proposed method was applied to the determination of thiamine in pharmaceutical preparation. Three different formulations were purchased from the local market. Not less than 20 thiamine tablets were weighed, ground to a fine powder and mixed. A sample equivalent to approximately 100 $\mathrm{mg}$ of thiamine was weighed accurately, transferred into a 250 $\mathrm{mL}$ calibrated flask and made up to volume with deionized water. After filtering, aliquots of solution were diluted by a factor of $10^{4}$ for the analysis. The measured contents were listed in Table 2.

\section{Conclusion}

A simple, rapid, sensitive and selective spectrophotometric method was developed for the analysis thiamine in Pharmaceuticals. Factors affecting the determination of thiamine were studied. The proposed procedures could be applied to quality-control analysis of the investigated drug.

\section{References}

[1]. Perez-Ruiz, T.; Martinz-Lozano, C.; Sanz, A.; Guillen, A. Biomed. Anal. 2004, 34, 551-557.

[2]. Chin, H. B. Methods of vitamin assay, $3^{\text {rd }}$ ed., Interscience Publishers, New York, 1966, Chap. 6, pp. 123-142.

[3]. Karlberg, B.; Thelender, S. Anal. Chim. Acta 1980, 114, 129-136.

[4]. Grekas, N.; Calokerinos, A. C. Talanta 1990, 37, 1043-1048.

[5]. Martinez-Lozano, C.; Perez-Ruiz, T.; Tomas, V.; Abellan, C. Analyst 1990, 115, 217-220.

[6]. Perez-Ruiz, T.; Martinez-Lozano, C.; Tomas, V.; Ibarra, I. Talanta 1992, 39, 907-911.

[7]. Calatayud, J. M.; Gomez-Bentio, C.; Gimenez, D. J. Pharm. Biomed. Anal. 1990, 8, 667-670.
[8]. Kssube, K.; Abe, K.; Ishiguro, Y.; Ishikawa, S.; Hosida, H. Chem. Pharm. Bull. 1983, 31, 3589-3594.

[9]. Danet, A. F.; Calatayud, J. M. Talanta 1994, 41, 2147-2151.

[10]. Chen, H.; Cao, X.; Fang, Q.; Zhu, J. Analyst 1998, 123, 1017-1021.

[11]. Vinas, P.; Lopez-Erroz, C.; Cerdan, E. J.; Campillo, N. Mikrochim. Acta 2000, 134, 83-87.

[12]. El-Gindy, A.; El-Yazby, F.; Mostafa, A.; Maher, M. M. J. Pharm. Biomed. Anal. 2004, 35(4), 703-713.

[13]. Tietz, N. W. Textbook of Clinical Chemistry, W. B. Saunders, Philadelphia, PA, 1986.

[14]. Costa-Neto C. O.; Pereira A. V.; Aniceto C.; Fatibello-Filho O. Talanto 1999, 48(3), 659-667.

[15]. Khan, M. A.; Jin, S. O.; Lee, S. H.; Chung, H. Y. Luminescence 2009, 24(2), 73-78.

[16]. Mohamed, A. M. I.; Mohamed, H. A.; Abdel-Latif, N. M.; Mohamed, M. R. J. AOAC Inter. 2011, 94(6), 1758-1769.

[17]. Szpikowska-Sroka, B. J. Anal. Chem. 2013, 68(3), 218-222.

[18]. Miller, J. C.; Miller, J. N. Statistics for Analytical Chemistry, 3rd ed. Horwood, Chichester, UK, 1993. 